\title{
ACID RAIN \& THE HARM TO THE ENVIRONMENT
}

\author{
Zohair Khalaf Ismail, Ph. D. \\ Department of Chemical Engineering; Faculty of Engineering Technology \\ Al-Balqa Applied University; Marka-Amman, Box: 15008, Jordan
}

Subhi K. Abderrezaq, Ph. D. REM.

City University-Tricities, WA 99352 USA

(Received December 31, 2005 Accepted March 1, 2006)

\begin{abstract}
One of the by-products of everyday life is acid rain. While acid rain is composed of several different pollutants, the two main ones are sulfur dioxide $\left(S O_{X}\right)$ and nitrogen oxides $\left(N O_{X}\right)$. Acid rain may also arrive in several different ways. It may show up in the form of rain, mist, snow, fog, or dry gas. $S O_{X}$ are produced by coal-burning smelters, power plants, and factories. $N O_{X}$ are produced by burning fuels such as gasoline in the cars and oil in the homes. Electric utility plants generate approximately 70 percent of annual $\mathrm{SO}_{X}$ emissions and 30 percent of $\mathrm{NO}_{X}$ emissions in the United States. Mobile sources also contribute a large amount to NOX emissions. Damage caused by acid rain ranges from respiratory health problems in humans to acidification of bodies of water and the loss of species of fish, and also the damage to forests and the soil needed for the trees to grow. There have been several laws and regulations passed to try and control the levels of acid rain. The Clean Air Act Amendments of 1990, being the main one to be passed and put into use. Once an individual and $\backslash$ or industry performs a cost benefit analysis the decision will be an effortless. Reduction of the pollutants that cause acid rain needs to be implemented.
\end{abstract}

KEYWORDS: Acid rain, sulfur dioxide.

\section{INTRODUCTION}

\section{Acid Rain \& the Risk to the Environment}

Within our environment there are many different activities, both natural and man made, that are destroying the environment. Acid rain is one of the by-products of every day life that is doing just that. "The term "acid rain" is used to describe rain or snow that has a $\mathrm{pH}$ lower than what is natural for a given area. $\mathrm{pH}$ is a measurement of how acidic or basic a material is and ranges from 0 to 14. Precipitation with a $\mathrm{pH}$ value less than 5 is considered acid rain." [1]. While this may slightly explain what the description of acid rain is, what and where does it come from? "Acid rain occurs when common air pollutants nitrogen oxides and sulfur dioxide combine with water in the atmosphere to 
form droplets of very weak acid" [2]. Acid rain does comprise of two pollutants: nitrogen oxides and sulfur dioxides. Individuals may state that the pollutants all come from the large industries, so they do not have anything to do with it, unfortunately that is not true. "Most sulfur dioxide is produced by coal-burning smelters, power plants and factories. Sulfur dioxide emissions form toxic compounds such as acid aerosols" [2]. This is only one half of the pollutants, the other half is produced by human activities. "Nitrogen oxides are produced when we burn fuels such as gasoline in our cars and oil in our homes, industries and power plants" [2]. Therefore, acid rain is not only a problem for large industries, but for everyone in the world. Acid rain is a global problem, as the winds move the pollutants in the air in new directions affecting all towns, states, and countries that it comes across. The name acid rain can also be misleading, causing people to think that it only comes in the form of rain. The truth of the matter is that it comes in the form of dry gas, rain, snow, mist, or fog.

It should be mentioned that the largest contributor of these pollutants is. "Electric utility plants account for about 70 percent of annual sulfur dioxide $\left(\mathrm{SO}_{2}\right)$ emissions and 30 percent of nitrogen oxide (NOx) emissions in the United States. Mobile sources (transportation) also contribute significantly to NOx emissions" [3]. From these figures one can see that plants do contribute quite a large amount of these pollutants into the air. Although, at the same time anybody drives a vehicle of any sort (car, train, bus, truck, etc.) can share the problem. So while there is probably one sector of the population that is more at fault than others, it is a problem for everyone in the world. As mentioned earlier, acid rain is damaging the environment and humans as well.

\section{BACKGROUND}

Acid rain is related to several health problems of humans, usually respiratory problems. Also, it causes to and $\backslash$ or aggravates certain types of lung disorders due to high levels of sulfur dioxide" [4]. Therefore, the majority of people in the world should band together to solve the problem. "Studies at Havard University have suggested a relationship between acidic sulfate levels and increased levels of morbidity (sickness) and mortality" [4]. Yet another instance that justifies the move to solve the problem of acid rain. As with other pollutants in the environment, acid rain does affect people differently. "Still growing, still developing, children are more vulnerable than adults to air pollutants. They are also generally exposed to more air pollutants than adults because they breathe faster and, in the summer, spend more time outdoors being physically active" [2]. Another factor that will cause a person to be more at risk from acid rain than other people are ones that have pre-existing health problems. "Children, as well as adults, with heart or lung problems, especially asthma, are considered to be more at risk because of their sensitivity to air pollutants in general and, when air pollution levels are high, they may experience a worsening of their condition" [2]. While acid rain is damaging to humans it is also ruining the water sources of the world.

There are many types of water (streams, rivers, lakes, ponds, etc.) that seem to be affected by acid rain, the most are the ones that non-flowing or flow very slowly. "Acid rain primarily affects sensitive bodies of water, that is, a soil with a limited ability to neutralize acidic compounds (called "buffering capacity")" [3]. This is most likely due 
to the fact that the water flow is very slow and the water is not able to remove the contaminants from it. In recent years there have been several studies of the bodies of water in the U.S. by groups that are concerned with the acidification of the water. "Of the lakes and streams surveyed in a National Surface Water Survey (NSWS), acid rain has been determined to cause acidity in 75 percent of the acidic lakes and about 50 percent of the acidic streams" [3]. The acidification of the water causes another problem and that is the loss of fish within these bodies of water.

This loss can not only affect the ecosystem, due to loosing one of its species, but also the livelihood of some people that rely on that specific species of fish to survive. "In some sensitive lakes and streams, acidification has completely eradicated fish species, such as the brook trout, leaving these bodies of water barren. In fact, hundreds of the lakes in the Adirondacks surveyed in the NSWS have acidity levels indicative of chemical conditions unsuitable for the survival of sensitive fish species" [3]. Another aspect of the environment that is affected by acid rain that can also affect humans is the damage to the forests.

As with the human health problems, acid rain has been implicated in being part of the damage to the forests in the world. "Acidic deposition seems to impair the tree's growth in several ways; for example, acidic cloud water at high elevations may increase the susceptibility of the red spruce to winter injury." [3]. Not only does acid rain cause damage to the trees when it falls on them as rain, but it also causes damage when it is absorbed by soil. Once absorbed by the soil it is then taken in by the roots of the trees and may cause damage internally. "As acid rain moves through the soils, it can strip away vital plant nutrients through chemical reactions, thus posing a potential threat to future forest productivity." [3]. One may wonder, if acid rain is such a danger to environment and to humans, are there any controls and $\backslash$ or laws concerning this problem.

"The U.S. Geological Survey (USGS) has not only been actively studying acid rain for the past 15 years, but has played a key role in establishing and maintaining the only nationwide network of acid rain monitoring stations" [1]. Through recent years there have been increasing studies conducted and laws passed dealing with the control and possible reduction of acid rain. "In fact, the Clean Air Act Amendments which became law in 1990 calls for a 10 million ton reduction in annual emissions of sulfur dioxide $\left(\mathrm{SO}_{2}\right)$ in the United States by the year 2010 , which represents an approximately 40 percent reduction in anthropogenic emissions from 1980 levels" [5]. As stated earlier, this is not a problem that affects only some individuals (plants and utilites) it is one that is a world wide problem. Countries of air pollution concerned can very easily become another countries problem with the blowing of the wind. Therefore, acid rain is one problem that needs everyone's cooperation in dealing with and trying to solve it. This will include both governments and industry working hand in hand to try and reduce the levels of acid rain. "Canada and the United States have signed an Air Quality Agreement committing both countries to major reductions in emissions that cause acid rain" [2]. While governments and industry are working on this problem and the individuals should also work at reducing the pollutants that will cause acid rain. Some methods an individual can use some methods to reduce the amount of pollutant 
generation. He should drive only when necessary, walk, or use a bicycle instead. If planning on purchasing a new car, buy a fuel efficient one. At homes individuals can upgrade and maintaining the heating system, windows and doors, and to dispose of chemicals properly. The main thing an individual can do is to think of energy conservation and rationalization to reduce the amount of pollutants produced.

A barrier that may come into play at this point is whether or not it is worth it. Is it in the individual's self-interest to perform the necessary steps to reduce the amount of pollutants that cause acid rain? When one takes in the available information on the subject it would seem to be worth it. Although at the end it will remain totally up to the individual and $\backslash$ or industry. In this argument, as with any one, there will be the supporters of reduction due to the dangers to the environment humans and there will be opponents of reduction due to the projected costs of accomplishing the reduction.

\section{CONCLUSIONS}

In conclusion, when a human being comes to the point of making a decision concerning the problem of acid rain performance of a cost $\backslash$ benefit analysis should be done. This is a way to weigh the cost of the steps needed to reduce the pollutants against the benefits they will enjoy. costs that have been studied the individual must weigh them against the benefits. Costs related to the health problem caused by acid rain should be evaluated as well. Damage due to acid rain has been found to harm the forests of the world. The benefits shall include cleaner air to breathe, cleaner water for the fish, and less damage to the forests. Bring to this, the lessened danger to the children, the continued livelihood for the fishermen, and lessened damage to buildings, it becomes an effortless decision. That is, every person and industry must do their part in reducing the amount of pollutants allowed in the atmosphere. Only when it becomes an all encompassing goal of everyone will there be a chance of the solution being reached.

\section{REFERENCES}

[1] Nilles, J. Gordon., Schroder, L., USGS Tracks Acid Rain. U.S. Geological Survey. Microsoft Internet Explorer. Available Internet: ttp://btdqs.usgs.gov/jgordon/arfs.html.

[2] Air Care : A parent's guide to air quality and health. Microsoft Internet Explorer. Available Internet: http://atlenv.ns.doe.ca/udo/air.html.

[3] Environmental Benefits Fact Sheet. (1995 July 21). Acid Rain Program. Microsoft Internet Explorer. Available Internet:

http://www.epa.gov/docs/acidrain/envben.html.

[4] Ciampa, Michelle. (1996 April 30). Acid Rain: Harmful to Humans. Microsoft Internet Explorer.

[5] Human Health Benefits-Executive Summary. Microsoft Internet Explorer. Available Internet: http://www.epa.gov/docs/acidrain/effects/healthrx.html. 


\section{الأمطار الحمضية وخطورتها على البيئة}

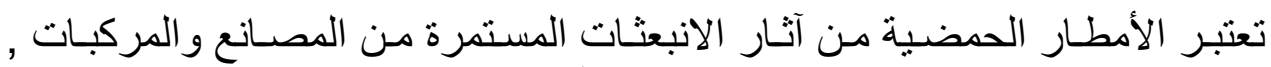

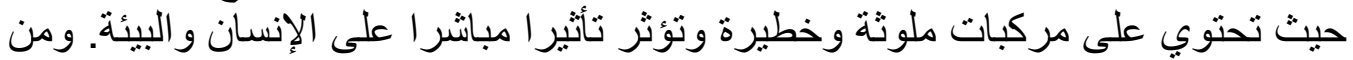

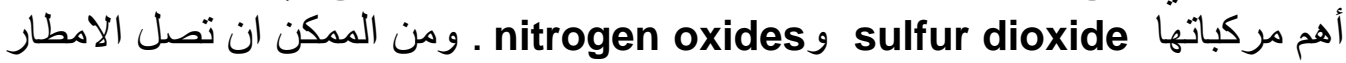

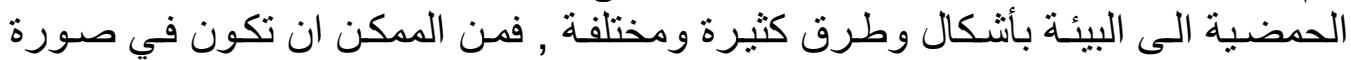

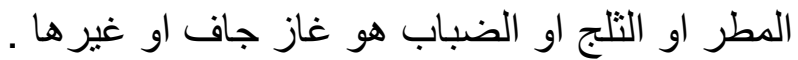

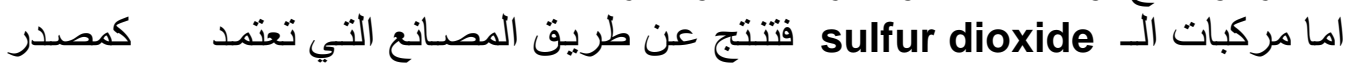

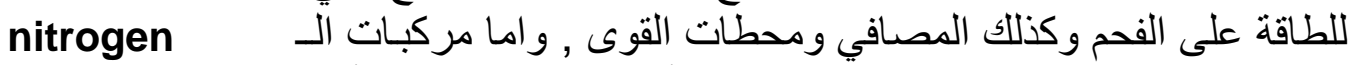
oxides المركبات واستخدام انو اع الوقود المختلفة في البيوت السكنية وغير هاعها .

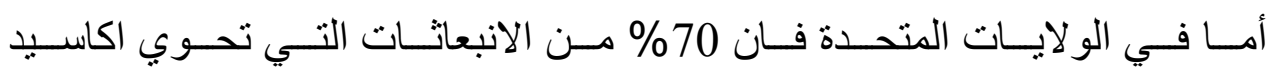

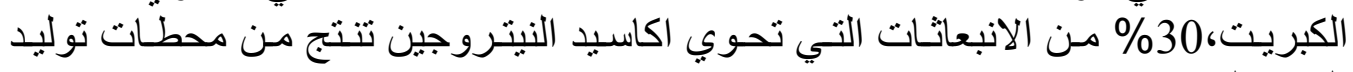

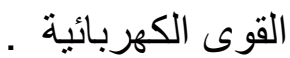
لقد استدعى أمر الأمطار الحمضية شديدة الخطورة إلى وجود قو انين صـارمة وشديدة

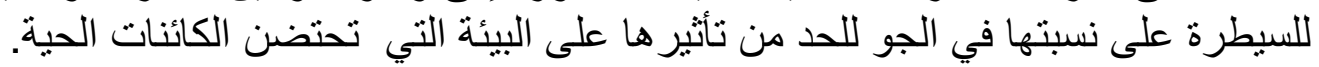

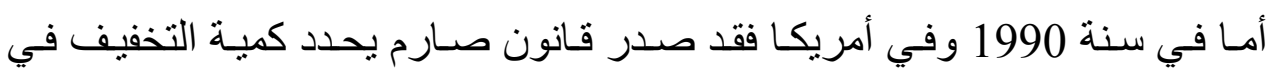

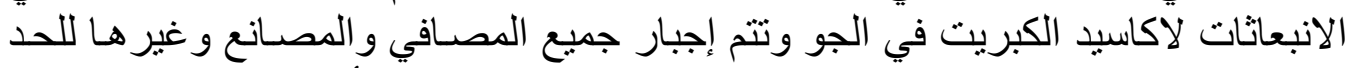

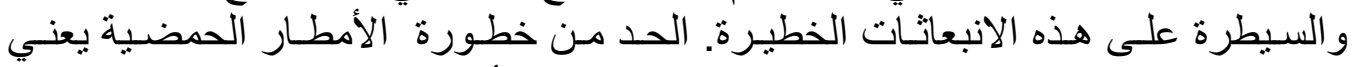
انتعاش بيئي نوعي و هذا يؤدي إلى انتعاش الحياة على الأرض. 